\title{
Approximal Plaque Index, parameters of calcium-phosphate and iron metabolism and the quality of life of hemodialysis patients
}

\begin{abstract}
Introduction. Hemodialysis patients require high standards in the field of dental diseases prevention and also in pharmacological and dialysis methods of combating biochemical disorders. It is necessary to question the methods of monitoring oral hygiene quality among hemodialysis patients.

Aim. The aim of this study was to determine the relationship between Approximal Plaque Index (API) and the quality of life and biochemical parameters of the calcium, phosphate and iron metabolism.

Material and methods. The study was conducted on a group of 124 individuals -65 women (52\%) and 59 men (48\%) aged 24-90, volunteered to undergo hemodialysis in chronic renal failure, who consented to participate in this study. All participants of the study were treated for at least 6 months, through repeated hemodialyses in dialysis centers in Lublin. The dental examination was performed and Approximal Plaque Index (API) was determined. The Polish version of the quality of life questionnaire SF-36 was used. The values of urea, serum creatinine concentration, serum level of calcium, serum phosphorus, parathormone, transferrin, ferritin, and iron were also under control. The Kruskal-Wallis H test and Spearman Rank Correlation was used.

Results. Patients with optimal API reported higher levels of iron and lowest concentration of transferrin and serum phosphorus before HD. Patients who were characterized by high levels of phosphate and parathyroid hormone evaluated their functioning in the emotional sphere as worse compared to others. Higher concentrations of iron and transferrin favor a better sense of the quality of life.

Conclusions. Lower concentrations of phosphate before hemodialysis and higher iron levels contribute to maintaining optimal interdental hygiene in patients treated with renal replacement therapy. Normalization of biochemical parameters of calciumphosphate and iron metabolism promotes a sense of better quality of life among patients on chronic hemodialysis. The level of interdental hygiene does not distinguish between general indicators of the sense of quality of life.
\end{abstract}

Keywords: Approximal Plaque Index, quality of life, end stage renal disease, calcium-phosphate metabolism, hemodialysis.

DOI: $10.1515 /$ pjph-2016-0037

\section{INTRODUCTION}

Due to various pathologies co-existing in hemodialysis patients in the course of end-stage renal disease (ESRD), they constitute a special group. This comorbidity, including among others, uremic disorders, calcium-phosphate and iron metabolism, indicates a negative impact on the oral health, as it is estimated that over $90 \%$ of patients with ESRD treated with renal replacement therapy, exhibit pathology within the oral cavity and the dental apparatus [1]. Attention is also paid to the fact that within this group the following symptoms are prevalent: uremic fetor, xerostomia, pale mucous membranes, uremic stomatitis, periodontal disease, bleeding and gingivitis, enamel hypoplasia secondary to alterations in calcium and phosphorus metabolism, the tendency to the formation of plaque induced by the increase in the level of urea in the saliva $[2,3]$. A major problem for the condition of the dental organ is the occurrence of renal osteodystrophy [4]. Furthermore, previous studies have shown that in patients with chronic renal failure, increase in serum phosphorus level, serum PTH level and salivary phosphorus level induces the formation of dental cavities [5]. Latest reports also analyze the relationship between the level of urea in the serum and the quality of the oral environment [6]. the time of chronic hemodialysis treatment also influences the oral health. It has been proven that patients who were treated for at least 37 months had a worse state of the dental apparatus than those who had been treated for less than 3 years [7].

In order to prevent dental apparatus pathologies, patients undergoing hemodialysis require high standards in the field

\footnotetext{
${ }^{1}$ Chair and Department of Paedodontics, Medical University of Lublin, Poland

${ }^{2}$ Department of Ethics and Human Philosophy, Medical University of Lublin, Poland

${ }^{3}$ Department of Nephrology, Medical University of Lublin, Poland
} 
of dental diseases prevention and also in pharmacological and dialysis methods of combating biochemical disorders [8]. This requires good quality cooperation between patients and the medical staff. Regarding the last factor, it is necessary to take into account psychosocial aspects, which can influence this cooperation and the practical application of recommendation of both the dentist and nephrologist. Based on recent medical literature, it is necessary to question the methods of monitoring of oral hygiene quality of patients on chronic hemodialysis programs. Another important practical problem is determining the correlations between the state of oral cavity,

TABLE 1. The characteristic of the study group in terms of hemodialysis adequacy indicators and calcium, phosphate and iron metabolism.

\begin{tabular}{|c|c|c|c|c|c|}
\hline $\begin{array}{l}\text { Hemodialysis adequacy } \\
\text { and biochemical } \\
\text { indicators }\end{array}$ & $\mathbf{N}$ & $\mathbf{M}$ & Min. & Max. & SD \\
\hline $\mathrm{KT} / \mathrm{V}$ & 124 & 1.35 & 0.22 & 5.35 & 0.50 \\
\hline URR [\%] & 124 & 71.24 & 19.36 & 90.68 & 9.03 \\
\hline Urea before HD [mg/dl] & 124 & 120.25 & 43.60 & 203.50 & 32.28 \\
\hline Urea after HD [mg/dl] & 124 & 35.89 & 10.00 & 164.10 & 19.05 \\
\hline Creatinine before $\mathrm{HD}[\mathrm{mg} / \mathrm{dl}]$ & 124 & 7.69 & 2.80 & 12.60 & 2.35 \\
\hline Calcium before HD [mg/dl] & 124 & 9.21 & 6.70 & 12.30 & 0.99 \\
\hline Calcium after HD [mg/dl] & 124 & 9.41 & 8.10 & 11.20 & 0.68 \\
\hline $\begin{array}{l}\text { Serum phosphorus before } \\
\text { HD }[\mathrm{mg} / \mathrm{dl}]\end{array}$ & 124 & 5.33 & 2.20 & 11.80 & 1.60 \\
\hline $\begin{array}{l}\text { Serum phosphorus after } \\
\text { HD [mg/dl] }\end{array}$ & 124 & 2.58 & 1.40 & 4.20 & 0.65 \\
\hline Parathormone [pg/ml] & 124 & 441.75 & 2.00 & 4310.00 & 531.59 \\
\hline $\mathrm{CRP}[\mathrm{mg} / \mathrm{l}]$ & 124 & 10.90 & 0.14 & 101.00 & 17.97 \\
\hline Transferrin $[\mathrm{mg} / \mathrm{dl}]$ & 124 & 188.74 & 33.00 & 368.00 & 47.93 \\
\hline Ferritin [ng/ml] & 124 & 436.81 & 15.00 & 2290.00 & 403.08 \\
\hline Iron [ug/dl] & 124 & 69.88 & 25.00 & 223.00 & 29.51 \\
\hline
\end{tabular}

URR- urea reduction ratio; HD-hemodialysis; CRP- C-reactive protein;

Normal range: Urea: 17-50; Creatinine: 0.7-1.2; Calcium: 8.8-11.0; Serum phosphorus:

4.4-8.7; Parathormone: 15-65; CRP-0-5.0; Transferrin: 130-360; Ferritin: 30-400; Iron: 59-158 the dental organ and biochemical parameters monitored during standard hemodialysis. In order to solve these problems, it is possible to look at the Approximal Plaque Index (API) to monitor the health of the oral cavity to enable the assessment of the presence of bacterial plaque in the interdental spaces. Only few studies conducted among hemodialysis patients take this factor into account [9].

\section{AIM}

The aim of this study was to determine the dependency between API and the quality of life and biochemical parameters of the calcium, phosphate and iron metabolism.

\section{MATERIAL AND METHODS}

The research was conducted on a group of 124 volunteers on hemodialysis in chronic renal failure aged 24-90 ( $\mathrm{M}=65.47$; $\mathrm{SD}=15.65$ ), who consented to participate in this study. All participants of the study were treated for at least 6 months by repeated hemodialysis in dialysis centers in Lublin. This group consisted of 65 women (52\%) and 59 men (48\%). The average dose of dialysis $(\mathrm{kt} / \mathrm{V})$ was 1.35 and the urea reduction rate was (URR) $71.24 \%$. During research other hemodialysis adequacy indicators such as the values of urea, serum creatinine concentration, serum level of calcium, serum phosphorus, parathormone, transferrin, ferritin, and iron were also under control. The characteristics of the study group in relation to the hemodialysis adequacy indicators and biochemical parameters are shown in Table 1.

Prior to hemodialysis, a dental examination was performed during which the presence of dental plaque was diagnosed in quadrants 1 and 3 of the proximal surface of the oral cavity and in the quadrants 2 and 4 of the proximal surface of the buccal cavity. Plaque was seen with the use of oral gavage. Based on this study Approximal Plaque Index was determined according to the following scheme: $100-70 \%$ - poor, $70-40 \%$ - average,

TABLE 2. Differences between hemodialysis adequacy and the API conditioned biochemical indicators.

\begin{tabular}{|c|c|c|c|c|c|c|c|c|c|c|c|}
\hline & \multicolumn{8}{|c|}{ Approximal Plaque Index (API) } & \multirow{2}{*}{\multicolumn{2}{|c|}{$\begin{array}{c}\text { Kruskal-Wallis } \\
\text { H Test }\end{array}$}} & \multirow{3}{*}{$\begin{array}{r}\text { Post-hoc } \\
\text { (test NIR) }\end{array}$} \\
\hline & \multicolumn{2}{|c|}{$\begin{array}{c}<25 \% \\
N=23(1)\end{array}$} & \multicolumn{2}{|c|}{$\begin{array}{c}39-25 \% \\
N=32(2)\end{array}$} & \multicolumn{2}{|c|}{$\begin{array}{c}70-40 \% \\
N=47(3)\end{array}$} & \multicolumn{2}{|c|}{$\begin{array}{l}100-70 \% \\
N=22(4)\end{array}$} & & & \\
\hline & $\mathbf{M}$ & SD & M & SD & M & SD & $\mathbf{M}$ & SD & $\mathbf{H}$ & $\mathbf{p}$ & \\
\hline $\mathrm{KT} / \mathrm{V}$ & 1.32 & 0.22 & 1.34 & 0.37 & 1.38 & 0.73 & 1.42 & 0.21 & 1.98 & 0.578 & - \\
\hline URR [\%] & 72.00 & 6.96 & 71.48 & 7.55 & 70.03 & 11.28 & 74.73 & 4.64 & 3.71 & 0.295 & - \\
\hline Urea before HD [mg/dl] & 127.66 & 30.65 & 126.98 & 29.87 & 114.63 & 33.81 & 115.90 & 35.31 & 2.71 & 0.438 & - \\
\hline Urea after HD [mg/dl] & 36.05 & 13.35 & 37.89 & 15.20 & 36.47 & 25.32 & 29.24 & 10.25 & 3.40 & 0.334 & - \\
\hline Creatinine before HD & 7.91 & 2.11 & 8.56 & 2.32 & 7.28 & 2.45 & 7.38 & 2.55 & 4.00 & 0.262 & - \\
\hline Calcium before HD [mg/dl] & 8.97 & 1.19 & 9.00 & 1.05 & 9.42 & 0.79 & 9.34 & 1.09 & 5.04 & 0.169 & - \\
\hline Calcium after HD [mg/dl] & 9.63 & 0.62 & 9.23 & 0.63 & 9.32 & 0.54 & 9.80 & 0.99 & 4.31 & 0.230 & - \\
\hline Serum phosphorus before HD [mg/dl] & 4.83 & 1.51 & 6.10 & 1.85 & 5.07 & 1.36 & 5.49 & 1.33 & 9.86 & 0.020 & $\begin{array}{l}1<2 \\
2>3\end{array}$ \\
\hline Serum phosphorus after HD [mg/dl] & 2.43 & 0.80 & 2.55 & 0.52 & 2.89 & 0.65 & 2.50 & 0.70 & 3.05 & 0.384 & - \\
\hline Parathormone $[\mathrm{pg} / \mathrm{ml}]$ & 308.78 & 296.50 & 422.10 & 343.05 & 515.76 & 690.85 & 565.40 & 663.63 & 3.65 & 0.302 & - \\
\hline $\mathrm{CRP}$ & 1.16 & 1.26 & 6.74 & 8.10 & 13.77 & 22.31 & 9.19 & 6.71 & 3.57 & 0.312 & - \\
\hline Transferrine $[\mathrm{mg} / \mathrm{dl}]$ & 173.39 & 32.98 & 184.60 & 36.08 & 201.41 & 57.99 & 178.33 & 46.73 & 7.97 & 0.047 & $1<3$ \\
\hline Ferritine $[\mathrm{ng} / \mathrm{ml}]$ & 481.89 & 363.07 & 465.59 & 446.27 & 390.13 & 351.80 & 531.75 & 588.08 & 1.16 & 0.763 & - \\
\hline Iron [ug/dl] & 88.30 & 39.29 & 68.08 & 20.52 & 67.12 & 28.22 & 60.76 & 24.98 & 8.22 & 0.042 & $\begin{array}{l}1>2 \\
1>3 \\
1>4\end{array}$ \\
\hline
\end{tabular}


$39-25 \%$ - rather good, $<25 \%$ - optimal hygiene. In order to determine their daily functioning, patients were asked to complete a questionnaire created on the basis of the Polish version of the quality of life questionnaire SF-36 [10-13] and questions regarding their socio-demographic situation. The SF-36 questionnaire was designed to determine the patients' subjective opinion of their quality of life. It consists of 11 questions, containing 36 statements that specify 8 detailed components: Physical Functioning, Role-Physical, Role-Emotional, Bodily pain, Vitality, Mental Health, Social Functioning and General Health. The enumerated components focus on two main areas: physical and mental health. The overall quality of life indicator is the sum of the obtained points from all 36 statements. The interpretation of the Polish version of the SF-36 assumes that the higher the point value, the worse the quality of life within individual components. Statistical analyses were performed using Statistica 10.0 PL. In order to evaluate intergroup differences, the Kruskal-Wallis $\mathrm{H}$ test was used. Statistically significant dependencies were identified using the nonparametric Spearman Rank Correlation test.

\section{RESULTS}

With reference to the API index, it was found that within the study group the largest proportion of patients were characterized by an average hygiene of interdental areas (API: $70-40 \%$ ). During the first stage of data analysis, differences between various subgroups of patients defined by the AP Index with respect to the biochemical parameters were described (Table 2). On the basis of the Kruskal-Wallis test it was determined that patients with highest i.e. optimal proximal surface hygiene were characterized by lowest concentration of phosphate and transferrin. This group was also characterized by a statistically significant higher level of iron concentration in blood serum (Table 2). No statistically significant differences were observed between the two groups in terms of either the indicator of dialysis dose $(\mathrm{kt} / \mathrm{V})$ or the parameters defining the hemodialysis adequacy.

In the second stage of data analysis, differences were determined within individual components of the SF-36 in view of the Approximal Plaque Index (API) (Table 3). Based on the Kruskal-Wallis test, statistically significant differences were observed in two components of the SF-36 (Table 3). Patients

TABLE 3. Differences in the quality of life (SF-36) conditioned by the Approximal Plaque Index.

\begin{tabular}{|c|c|c|c|c|c|c|c|c|c|c|c|}
\hline \multirow{3}{*}{ Factors of SF-36 } & \multicolumn{8}{|c|}{ Approximal Plaque Index (API) } & \multirow{2}{*}{\multicolumn{2}{|c|}{$\begin{array}{c}\text { Kruskal-Wallis } \\
\text { H Test }\end{array}$}} & \multirow{3}{*}{$\begin{array}{c}\text { Post-hoc } \\
\text { (test NIR) }\end{array}$} \\
\hline & \multicolumn{2}{|c|}{$\begin{array}{c}<25 \% \\
N=23(1)\end{array}$} & \multicolumn{2}{|c|}{$\begin{array}{l}39-25 \% \\
N=32(2)\end{array}$} & \multicolumn{2}{|c|}{$\begin{array}{c}70-40 \% \\
N=47(3)\end{array}$} & \multicolumn{2}{|c|}{$\begin{array}{l}100-70 \% \\
N=22(4)\end{array}$} & & & \\
\hline & $\mathbf{M}$ & SD & $\mathbf{M}$ & SD & $\mathbf{M}$ & SD & $\mathbf{M}$ & SD & $\mathbf{H}$ & p & \\
\hline Physical Functioning (PF) & 28.06 & 16.40 & 32.68 & 16.40 & 32.20 & 14.66 & 28.25 & 16.78 & 1.36 & 0.716 & - \\
\hline Role-Physical (RP) & 3.89 & 6.76 & 9.20 & 8.74 & 4.13 & 7.24 & 3.75 & 7.11 & 9.00 & 0.029 & $\begin{array}{l}1<2 \\
2>3 \\
2>4\end{array}$ \\
\hline Role-Emotional (RE) & 1.39 & 4.13 & 5.00 & 6.61 & 1.38 & 3.20 & 0.42 & 1.44 & 10.41 & 0.015 & $\begin{array}{l}1<2 \\
2>3 \\
2>4\end{array}$ \\
\hline Bodily pain (BP) & 3.72 & 3.25 & 5.52 & 2.74 & 4.35 & 2.98 & 4.33 & 3.14 & 3.96 & 0.265 & - \\
\hline Vitality (VT) & 11.44 & 3.48 & 12.00 & 5.02 & 10.95 & 3.99 & 10.08 & 3.09 & 2.82 & 0.420 & - \\
\hline Mental Health (MH) & 6.11 & 2.35 & 7.52 & 4.17 & 7.15 & 4.04 & 5.33 & 3.11 & 2.63 & 0.453 & - \\
\hline Social Functioning (SF) & 1.11 & 1.49 & 1.08 & 1.61 & 0.95 & 1.43 & 1.00 & 1.48 & 0.34 & 0.953 & - \\
\hline General Health $(\mathrm{GH})$ & 15.56 & 2.12 & 14.48 & 3.06 & 14.08 & 3.10 & 16.42 & 2.50 & 7.56 & 0.056 & - \\
\hline Physical Health & 51.22 & 23.41 & 61.88 & 24.98 & 54.75 & 20.59 & 52.75 & 24.48 & 2.72 & 0.436 & - \\
\hline Mental Health & 20.06 & 8.85 & 25.60 & 14.00 & 20.43 & 9.48 & 16.83 & 7.11 & 4.43 & 0.219 & - \\
\hline SF-36 Total & 73.67 & 31.25 & 90.00 & 34.60 & 77.25 & 27.76 & 72.17 & 28.54 & 4.67 & 0.197 & - \\
\hline
\end{tabular}

TABLE 4. Spearman's rank correlation coefficient between components of the quality of life questionnaire (SF-36) and the indicators of calcium, phosphate and iron metabolism.

\begin{tabular}{|c|c|c|c|c|c|c|c|c|c|c|c|}
\hline & \multicolumn{11}{|c|}{$\begin{array}{c}\text { Factors of SF-36 } \\
\text { Spearman Rank Correlation }\end{array}$} \\
\hline & $\mathbf{P F}$ & $\mathbf{R P}$ & $\mathbf{R E}$ & BP & VT & MH & SF & GH & $\begin{array}{c}\text { Physical } \\
\text { health }\end{array}$ & $\begin{array}{c}\text { Mental } \\
\text { health }\end{array}$ & $\begin{array}{r}\text { SF-36 } \\
\text { Total }\end{array}$ \\
\hline Calcium before HD & -0.07 & $-0.35 *$ & 0.01 & -0.15 & -0.06 & 0.06 & -0.10 & $-0.20 *$ & $-0.23 *$ & 0.00 & -0.17 \\
\hline Calcium after HD & -0.24 & -0.27 & 0.05 & -0.28 & -0.01 & -0.06 & -0.09 & -0.08 & $-0.29 *$ & -0.07 & -0.22 \\
\hline Serum phosphorus before HD & -0.17 & -0.04 & $0.25 *$ & 0.04 & -0.13 & -0.11 & -0.06 & -0.06 & -0.12 & -0.05 & -0.08 \\
\hline Serum phosphorus after HD & -0.16 & $-0.31 *$ & 0.25 & -0.19 & -0.20 & -0.19 & -0.22 & -0.14 & -0.25 & -0.20 & -0.20 \\
\hline Parathormone & 0.09 & -0.03 & $0.20 *$ & 0.10 & 0.08 & 0.00 & 0.06 & 0.01 & 0.07 & 0.10 & 0.10 \\
\hline CRP & 0.24 & $0.38 *$ & $-0.35 *$ & 0.22 & 0.16 & 0.03 & 0.20 & 0.30 & $0.37 *$ & 0.01 & 0.29 \\
\hline Transferrin & $-0.20 *$ & -0.19 & -0.09 & -0.19 & -0.09 & 0.05 & $-0.27 *$ & -0.17 & $-0.26 *$ & -0.12 & $-0.23 *$ \\
\hline Ferritin & -0.07 & 0.11 & -0.07 & -0.08 & -0.04 & 0.01 & 0.08 & 0.02 & -0.02 & -0.05 & -0.05 \\
\hline Iron & $-0.28 *$ & -0.02 & -0.16 & -0.13 & -0.15 & $-0.26 *$ & -0.08 & -0.13 & $-0.24 *$ & $-0.24 \%$ & $-0.26 *$ \\
\hline
\end{tabular}

PF-Physical Functioning; RP-Role-Physical RE-Role-Emotional; BP-Bodily pain; VT-Vitality; MH-Mental Health; SF-Social Functioning; GH-General Health. *p $<0.05$ 
characterized by relatively good interdental hygiene were also characterized by the highest number of obtained points i.e. they evaluated their quality of life in terms of physical (RP) and emotional (RE) functioning as low (Table 3).

By analyzing the correlation matrix obtained between the different components of quality of life questionnaire (SF-36) and selected biochemical indicators it should be noted that the higher the SP-36 score, the lower the evaluation of the patient's quality of life. Because of that, significant negative correlation in the direction of dependencies in Table 4 indicates that the higher the value of received biochemical indicators, the better the patients assessed their quality of life.

In accordance with these restrictions, certain detailed components of the SF-36 questionnaire correlated with the level of calcium in the serum before hemodialysis (Table 4)

Additionally, few significant positive correlations were observed. The relationship between Role-Emotional and the parathyroid level $(\mathrm{R}=0.20)$ and the phosphate level measured prior to dialysis $(\mathrm{R}=0.25)$ seem of particular importance (Table 4). They indicate that patients who were characterized by high levels of phosphate and parathyroid hormone evaluated their functioning in the emotional sphere as worse, when compared to others. A similar correlation was observed between RolePhysical and Physical Health and CRP (Table 4). It is necessary to note that in the broadest sense, which also includes the overall results of the SF-36 scale, a correlation was obtained in regards to the biochemical parameters of the iron metabolism. It has been demonstrated that patients on hemodialysis evaluated their quality of life in Physical Functioning, Physical Health and SF-36 Total the better, the higher the levels of transferrin and iron in blood serum (Table 4).

\section{DISCUSSION}

The level of interproximal hygiene is the result of internal homeostasis and the care for oral hygiene. Until now, only few authors attempted at linking API with determined biochemical indicators. For instance, studies conducted on patients with diabetes have not established a relationship between API values and the indicators of diabetes control (HbA1C) [14]. However, in case of end-stage renal failure, it is possible to identify the relationship between API markers of organism's homeostasis. Analysis of the results allows to formulate the assumption that, optimal interdental hygiene is conductive to high levels of iron and low levels of phosphate determined prior to dialysis. In turn, this assumption may lead to the conclusion that good dental condition may be conditioned by the stabilization of calcium, phosphate and oxide metabolism level. This suggestion is not undermined by the identification of statistically higher transferrin level among patients with average interdental hygiene in comparison to those with the optimal level of API. Although the analysis of correlations revealed that in the whole study group, higher levels of iron and transferrin favored the belief on higher life quality, the concentration of transferrin in blood serum of those on hemodialysis was influenced by numerous factors such as the level of iron or the severity of secondary anemia. This impedes the evaluation of iron metabolism based solely on transferrin level, in opposition to the iron level, which in this aspect is much more useful. An important issue to be resolved in future research programs is the question of initial conditioning of the relationship between iron metabolism parameters and API.
In medical literature suggestions arise that among people without ESRD, the existence of periodontitis and lower Approximal Plaque Index (API) may in turn cause anemia [15].

Previous reports suggested that worse oral hygiene may reduce the subjective feeling of high quality of life [16]. Analyzing the results of this study, it is possible to assume that there are no long lasting relations between API and life quality. Although statistically significant differences were obtained in two specific components of the SF-36 in relation to API, they did not translate into similar differences in the main components nor the overall result of the quality of life scale. What is more, the study revealed differences, which indicated that patients characterized by relatively good API (39-25\%) evaluated their quality of life as lowest in the physical (RP) and emotional (RE) functioning. These results can be an outcome of differences in the phosphate levels, determined before hemodialysis. This subgroup was characterized by the highest level of phosphates from the four separate subgroups created based on the API. This assumption is authenticated by the identified correlation according to which patients who were characterized by higher levels of phosphates in blood serum prior to hemodialysis evaluated their emotional functioning lowest. The rebalance of calcium and phosphate metabolism contributes to the improvement of sense of life's quality. Correlations were reported showing that the more standardized calcium level prior and after dialysis the more likely are the patients to declare a higher life quality in terms of physical health. It should be underlined that his regularity pertains only to patients who were treated with hemodialysis, as other studies conducted on a general population of patients treated by general practitioners obtained an opposite correlation between the sense of life quality and the calcium level in blood serum [17]. In studies conducted among patients on hemodialysis, no improvement of quality of life stated after the application of the dialysis fluid with a reduced concentration was reported [18]. This result may confirm the validity of our observations.

To conclude, it needs emphasizing that the introducing schemes of prevention and treatment of dental ailments for patients with end-stage renal diseases to the curricula of medical studies is a topic currently under discussion [19].

\section{CONCLUSIONS}

1. Lower concentrations of phosphate marked before hemodialysis and higher iron levels contribute to maintaining optimal interdental hygiene in patients treated with renal replacement therapy.

2. Normalization of biochemical parameters of calcium-phosphate and iron metabolism promotes a sense of better quality of life among patients on chronic hemodialysis.

2.1. Higher calcium levels both before and after hemodialysis promote a better sense of quality of life in terms of physical health

2.2. Higher concentrations of iron and transferrin favor a better sense of the quality of life both in terms of physical health, as well as in general.

3. The level of interdental hygiene does not distinguish between general indicators of the sense of quality of life. 


\section{REFERENCES}

1. de la Rosa García E, Mondragón Padilla A, Aranda Romo S, Bustamante Ramírez MA. Oral mucosa symptoms, signs and lesions, in end stage renal disease and non-end stage renal disease diabetic patients. Med Oral Patol Oral Cir Bucal. 2006;11:E467-73.

2. Jover Cerveró A, Bagán JV, Jiménez Soriano Y, Poveda Roda R. Dental management in renal failure: patients on dialysis. Med Oral Patol Oral Cir Bucal. 2008;13:E419-26.

3. Sharma DC, Pradeep AR. End stage renal disease and its dental management. N Y State Dent J. 2007;73:43-7.

4. De Rossi SS, Glick M Dental considerations for the patient with renal disease receiving hemodialysis. J Am Dent Assoc. 1996;127:211-9.

5. Imirzalioglu P, Onay EO, Agca E, Ogus E. Dental erosion in chronic renal failure. Clin Oral Investig. 2007;11:175-80.

6. Chen W, Laiho S, Vaittinen O, et al. Biochemical pathways of breath ammonia $(\mathrm{NH} 3)$ generation in patients with end-stage renal disease undergoing hemodialysis. J Breath Res. 2016;10:036011. doi: 10.1088/17527155/10/3/036011

7. Sekiguchi RT, Pannuti CM, Silva HT Jr, et al. Decrease in oral health may be associated with length of time since beginning dialysis. Spec Care Dentist. 2012;32:6-10.

8. Proctor R, Kumar N, Stein A, et al. Oral and dental aspects of chronic renal failure. J Dent Res. 2005;84:199-208.

9. Franek E, Blaschyk R, Kolonko A, et al. Oral hygiene in haemodialyzed patients with chronic renal failure. Wiad Lek. 2006;59:184-8.

10. Ware JE Jr, Sherbourne CD. The MOS 36-item short-form health survey (SF36). I. Conceptual framework and item selection. Med Care. 1992;30:473-83.
11. McHorney CA, Ware JE Jr, Raczek AE. The MOS 36-Item Short-Form Health Survey (SF-36): II. Psychometric and clinical tests of validity in measuring physical and mental health constructs. Med Care. 1993;31:247-63.

12. McHorney CA, Ware JE Jr, Lu JFR, Sherbourne CD. The MOS 36item ShortForm Health Survey (SF-36): III Tests of data quality, scaling assumptions, and reliability across diverse patient groups. Med Care 1994;32:40-46.

13. Tylka J, Piotrowicz R. Quality of life SF-36 questionnaire - the Polish version. Kardiol Pol. 2009;67:1166-9.

14. Kiedrowicz M, Dembowska E, Banach J, et al. A comparison of the periodontal status in patients with type 2 diabetes based on glycated haemoglobin levels and other risk factors. Adv Med Sci. 2015;60:156-61.

15. Anumolu VN, Srikanth A, Paidi K. Evaluation of the relation between anemia and periodontitis by estimation of blood parameters: A cross-sectional study. J Indian Soc Periodontol. 2016;20:265-72.

16. Kanaffa-Kilijanska U, Kaczmarek U, Kilijanska B, Frydecka D. Oral health condition and hygiene habits among adult patients with respect to their level of dental anxiety. Oral Health Prev Dent. 2014;12:233-9.

17. Dalemo S, Eggertsen R, Hjerpe P, et al. Quality of life and health care consumption in primary care patients with elevated serum calcium concentrations in - a prospective, case control, study. BMC Family Practice. 2014;15:84.

18. Taji Y, Morimoto T, Fukuhara S, et al. Effects of low dialysate calcium concentration on health-related quality of life in hemodialysis patients. Clin Exp Nephrol. 2005;9:153-7

19. Sturgill J, Howell S, Perry MM, Kothari H. Protocols for treating patients with end-stage renal disease: a survey of undergraduate dental programs. Spec Care Dentist. 2016;36:321-4. doi: 10.1111/scd.12197.

\section{Corresponding author}

Jarosław J. Sak

Department of Ethics and Human Philosophy, Medical University of Lublin

Staszica 4/6, 20-081 Lublin, Poland

E-mail: jareksak@tlen.pl

\section{Ministerstwo Nauki}

i Szkolnictwa Wyższego

"Wsparcie finansowe zagranicznych recenzentów publikacji w czasopiśmie PJPH” finansowane w ramach umowy 547/P-DUN/2016 ze środków Ministra Nauki i Szkolnictwa Wyższego przeznaczonych na działalność upowszechniającą naukę. 